\title{
Genotypic variability and relationships of Sorghum bicolor accessions from Java Island, Indonesia based on IRAP markers
}

\author{
IKA NUGRAHENI ARI MARTIWI ${ }^{1,2}$, LAURENTIUS HARTANTO NUGROHO ${ }^{1}$, BUDI SETIADI DARYONO ${ }^{1}$, \\ RATNA SUSANDARINI ${ }^{1, \vee}$ \\ ${ }^{1}$ Graduate Program in Biology, Faculty of Biology, Universitas Gadjah Mada. Jl. Teknika Selatan, Sekip Utara, Sleman 55281, Yogyakarta, Indonesia. \\ Tel./fax.: +62-274-580398, "email: ratna-susandarini@ugm.ac.id \\ ${ }^{2}$ Faculty of Science and Technology, Universitas Islam Negeri Sunan Kalijaga. Jl. Laksda Adisucipto, Sleman 55281, Yogyakarta, Indonesia
}

Manuscript received: 2 November 2020. Revision accepted: 17 November 2020.

\begin{abstract}
Martiwi INA, Nugroho LH, Daryono BS, Susandarini R. 2020. Genotypic variability and relationships of Sorghum bicolor accessions from Java Island, Indonesia based on IRAP markers. Biodiversitas 21: 5637-5643. Sorghum (Sorghum bicolor (L.) Moench) is a multifunctional crop with high adaptability to various habitats and thus it is important to assess the genotypic variability of this crop species. This study aimed to reveal the genotypic variability and relationships of sorghum accessions using inter-retrotransposon amplified polymorphism (IRAP) molecular markers. Twenty-three sorghum accessions were collected from smallholder farmers in three provinces of Java Island during the 2019 planting season. The IRAP profiles generated using 10 primer combinations produced 233 scorable bands, with degree of polymorphism 75-96.9\%. Cluster analysis using the neighbor-joining (NJ) method showed the formation of three groups corresponds to geographic origin of samples. The NJ dendrogram structure indicated high genotypic variability, and was supported by distribution pattern of accessions on the scatterplot constructed using principal coordinate analysis. The grouping of accessions did not correspond to classification of botanical races. Each group recognized from cluster analysis and principal coordinate analysis consisted of various races namely Bicolor, Guinea, Caudatum, and Kaffir. The fact that each group consisted of various botanical races indicated local adaptation and the maintenance of genotypic identity through farmers' selection in traditional cultivation practices. It could be concluded, therefore, that geographical proximity and the practice of seed exchange between different regions showed considerable influence on the genotypic relationships of sorghum accessions.
\end{abstract}

Keywords: Genotype, molecular characterization, retrotransposon, sorghum, taxonomic affinity

\section{INTRODUCTION}

Sorghum bicolor (L.) Moench is a member of the Poaceae family and considered as multi-beneficial crop with various uses. The grains are used for food, the leaves are used as animal feed, and the stem with high sugar content is processed for syrup, beverage, and biofuel (Dahlberg et al. 2011, Disasa et al. 2016). Accordingly, three variants of $S$. bicolor are known namely grain sorghum, forage sorghum, and sweet sorghum. S. bicolor has no genetic barrier, resulting in very wide intra-species variations (Berenji et al. 2011). Taxonomic study on $S$. bicolor accessions from Java Island based on morphological characters showed high variability as indicated by the existence of four botanical races namely Bicolor, Guinea, Caudatum, and Kaffir (Martiwi et al. 2020). This high morphological variability indicates high genotypic diversity among sorghum accessions.

Studies on estimation of genetic diversity among sorghum accessions based on phenotypic traits have been carried out by Chavan et al. (2010) based on 10 quantitative traits, while Tesfaye (2017) used 9 quantitative traits, and Mumtaz et at. (2018) used 7 morphological traits. Genetic diversity studies of sorghum using various molecular markers have been conducted in many countries, such as using combination of sequence data from cpDNA regions and the internal transcribed spacers (ITS) for sorghum in southern Africa (Ng'uni et al. 2010), the inter simple sequence repeats (ISSR) markers for sorghum from India and Syria (Alhajturki et al. 2011), and simple sequence repeats (SSR) markers for sorghum genotypes originated from India, Africa, USA and Portugal (Madhusudhana et al. 2012). The genetic diversity study of 30 sorghum genotypes from Pakistan by Raza et al. (2019) using RAPD (randomly amplified polymorphic DNA) showed that RAPD can be used as molecular marker in the analysis of phylogenetic relationships.

The use of molecular markers has the advantage of being unaffected by the environment. One group of molecular markers widely used in the assessment of genotypic variability and relationships are interretrotransposon amplified polymorphism (IRAP). IRAP markers are generated using the principle of amplifying regions between two long terminal repeats (LTRs), and can be produced with one or two primers (Kalendar et al. 1999). IRAP as molecular marker could produce high levels of polymorphism and is widely applied in studies of genetic diversity and cladistics relationships (Mansour 2008). There are advantages of using IRAP markers since there is no need for previous DNA restriction or ligation processes and the results of the PCR can be visualized in agarose gel (Gozukirmizi et al. 2015).

In sorghum, the proportion of retrotransposons is recorded as much as $54 \%$ of the total genome (Jiang and 
Ramachandran 2013). The use of IRAP markers in sorghum and other cereal crops has been reported in a number of studies. Genetic diversity study of $S$. halepense in Iran using IRAP markers with combinations of eight primers produced high level of polymorphism of $98.9 \%$ (Karimi and Saeidi 2015). The use of IRAP in the study of genetic variation in 89 wheat accessions resulted in $98.6 \%$ polymorphism (Farouji et al. 2015). This study aimed to reveal genotypic variability and relationships of S. bicolor accessions cultivated in Java Island using IRAP markers. Research on the genotypic variability and relationships of $S$. bicolor is important as a crucial step to document the genetic potentials for breeding improvement program of this species.

\section{MATERIALS AND METHODS}

\section{Plant materials}

Twenty-three S. bicolor accessions used in this study were obtained from three provinces in Java Island (Table 1). The plant materials were collected directly from the field of smallholder farmers. Fresh leaves at the third position of the shoot were used for extraction of genomic DNA.

\section{DNA extraction}

Genomic DNA extraction was carried out using cetyl trimethyl ammonium bromide (CTAB) method. Two grams of fresh leaf were cut into small pieces and put in a tube containing extraction buffer solution until all leaf samples were submerged. The leaf samples were crushed into fine paste using mortar and pestle. The sample was then poured into a $1.5 \mathrm{ml}$ tube, and $5 \mu \mathrm{L}$ of proteinase-K $(10 \mathrm{mg} / \mathrm{ml})$ was added and shaken until completely mixed. The mixture was incubated at $37^{\circ} \mathrm{C}$ for 30 minutes followed by second incubation process at $65^{\circ} \mathrm{C}$ for 30 minutes. During the incubation, the mixture was manually shaken for 1 minute at 10 minutes intervals. The mixture was then centrifuged at $8,000 \mathrm{x} \mathrm{g}$ for 10 minutes at room temperature. The supernatant (approximately $700 \mu \mathrm{L}$ ) was then carefully transferred to a new tube. A mixture of chloroform: isoamyl alcohol (24: 1) was added at the volume ratio of 1: 1. After being shaken for 2 minutes the mixture was centrifuged at $8,000 \times \mathrm{g}$ for 10 minutes, and the supernatant was transferred to a new tube. Precipitation process was done by adding cold chloroform: isoamyl alcohol (24: 1) with a volume ratio of 1: 1 and the mixture was shaken slowly, before adding $200 \mu \mathrm{L}$ of $4 \%$ PEG in $2 \mathrm{M} \mathrm{NaCl}$. Following the incubation for 15 minutes at $4^{\circ} \mathrm{C}$, the mixture was centrifuged at $8,000 \mathrm{x} g$ for 10 minutes. The supernatant was transferred to a new tube, and $2 / 3$ volume of isopropanol was added, and the mixture was incubated for 2 hours. After being centrifuged at $10,000 \mathrm{x} \mathrm{g}$ for 10 minutes, the supernatant was discarded and the DNA pellet was rinsed using $250 \mu \mathrm{L}$ of washing buffer by centrifuging at $8,000 \mathrm{x} g$ for 3 minutes. The subsequent washing process was carried out using $70 \%$ ethanol 3 times. The ethanol was then discarded and the DNA pellet was air-dried at room temperature before being dissolved in $50 \mu \mathrm{L} 1 \times \mathrm{TE}$ buffer and stored in a freezer at $-20^{\circ} \mathrm{C}$.

\section{PCR procedure}

IRAP fingerprinting data were generated through PCR using 10 combinations of primers derived from barley namely Sukkula (Shirasu et al. 2000), LTR 6150, 3'LTR 2 (Kalendar et al. 2000) and from bananas namely RTY1 and RTY2 (Teo et al. 2005). The primers used for generating IRAP fingerprinting were listed in Table 2. The PCR was performed in $15 \mu \mathrm{L}$ volume consisting of $50 \mathrm{ng}$ of genomic DNA, $200 \mu \mathrm{M}$ dNTPS, 1 unit of Taq Polymerase, 1 x PCR buffer solution (10 mm Tris-HCl, $\mathrm{pH} 8.3 ; 50 \mathrm{mM} \mathrm{KCl} ; 1.5$ $\mathrm{mM} \mathrm{MgCl}_{2}$ ) and $10 \mathrm{pmol}$ of each primer. The PCR was carried out with the following program: initial denaturation at $94^{\circ} \mathrm{C}$ for 4 minutes followed by 30 amplification cycles consisting of denaturation at $94^{\circ} \mathrm{C}$ for 1 minute, annealing for 1 minute at the temperature adjusted to particular primer combination as in listed Table 3 , elongation at $72^{\circ} \mathrm{C}$ for 2 minutes, and final extension at $72^{\circ} \mathrm{C}$ for 2 minutes. PCR products were visualized on $2 \%$ agarose gel (w/v) by electrophoresis method.

\section{Data analysis}

IRAP fingerprinting profiles were analyzed as binary data by giving a score of 1 for the presence and 0 for the absence of DNA fragments. The binary data were used to determine the genotypic relationships of 23 sorghum accessions using Neighbor-Joining clustering method based on Manhattan distance. A two-dimensional scatterplot figuring out affinities among accessions were constructed using principal coordinate analysis (PCoA). Cluster analysis and principal coordinate analysis were performed using PAST software version 4.2 (Hammer et al. 2001).

Table 1. List of sorghum accessions

\begin{tabular}{cl}
\hline Accession code & \multicolumn{1}{c}{ Origin (District, Province) } \\
\hline YJ1 & Gunungkidul, Yogyakarta \\
YJ2 & Gunungkidul, Yogyakarta \\
YJ3 & Gunungkidul, Yogyakarta \\
YJ4 & Sleman, Yogyakarta \\
YJ5 & Gunungkidul, Yogyakarta \\
YJ6 & Gunungkidul, Yogyakarta \\
YJ7 & Gunungkidul, Yogyakarta \\
YJ8 & Gunungkidul, Yogyakarta \\
YJ9 & Gunungkidul, Yogyakarta \\
YJ10 & Gunungkidul, Yogyakarta \\
YJ11 & Gunungkidul, Yogyakarta \\
CJ1 & Demak, Central Java \\
CJ2 & Demak, Central Java \\
CJ3 & Wonogiri, Central Java \\
CJ4 & Wonogiri, Central Java \\
CJ5 & Wonogiri, Central Java \\
CJ6 & Wonogiri, Central Java \\
EJ1 & Bojonegoro, East Java \\
EJ2 & Sumenep, East Java \\
EJ3 & Bojonegoro, East Java \\
EJ4 & Lamongan, East Java \\
EJ5 & Lamongan, East Java \\
EJ6 & Lamongan, East Java \\
\hline
\end{tabular}


Table 2. Primers used for generating IRAP fingerprinting

\begin{tabular}{llll}
\hline \multicolumn{1}{c}{ Primer } & \multicolumn{1}{c}{$\begin{array}{c}\text { Retrotransposon source } \\
\text { and direction }\end{array}$} & Sequence & Reference \\
\hline Sukkula & Sukkula (forward) & GATAGGGTCGCATCTTGGGCGTGA & Shirasu et al. (2000) \\
RTY2 & W1, W3, W7, W8 (forward) & TRGTARAGRAGNTGRAT & Teo et al. (2005) \\
RTY1 & W1, W3, W7, W8 (reverse) & CCYTGNAYYAANGCNGT & Teo et al. (2005) \\
3'LTR2 & BARE-1 (forward) & TGTTTCCCATGCGACGTTCCCCAACA & Kalendar et al. (2000) \\
LTR6150 & BARE-1 (reverse) & CTGGTTCGGCCCATGTCTATGTATCCACACATGGTA & Kalendar et al. (2000) \\
\hline Note: $Y=C$ or T: $\mathrm{N}=\mathrm{A}, \mathrm{G}, \mathrm{C}$ or $\mathrm{T} ; \mathrm{R}=\mathrm{A}$ or $\mathrm{G}$ & &
\end{tabular}

Note: $\mathrm{Y}=\mathrm{C}$ or $\mathrm{T} ; \mathrm{N}=\mathrm{A}, \mathrm{G}, \mathrm{C}$ or $\mathrm{T} ; \mathrm{R}=\mathrm{A}$ or $\mathrm{G}$

Table 3. Annealing temperatures for specific primer combinations

\begin{tabular}{lc}
\hline Primer combination & $\begin{array}{c}\text { Annealing } \\
\text { temperature }\left({ }^{\circ} \mathbf{C}\right)\end{array}$ \\
\hline Sukkula-Sukkula & 56.5 \\
Sukkula-RTY2 & 56.5 \\
RTY2-RTY2 & 47.5 \\
RTY1-3'LTR2 & 49.7 \\
3'LTR2-3'LTR2 & 50.5 \\
LTR6150-LTR6150 & 45.0 \\
RTY1W3-3'LTR2 & 47.5 \\
RTY1W7-3'LTR2 & 47.5 \\
RTY2W3-RTY2W3 & 47.5 \\
RTY2W8-RTY2W8 & 47.5 \\
\hline
\end{tabular}

\section{RESULTS AND DISCUSSION}

\section{Polymorphism of IRAP markers}

The IRAP fingerprinting profiles generated using 10 combinations of primers produced a total of 233 DNA bands ranging in size from 100 to $3,450 \mathrm{bp}$. Representation of IRAP fingerprinting patterns visualized on agarose gel was shown in Figure 1. The IRAP fingerprinting profile showed high polymorphisms in all primer combinations with an average degree of polymorphism was $90.6 \%$. The polymorphisms range from $75.0 \%$ for the RTY2-RTY2 to $96.9 \%$ for the Sukkula-Sukkula primer combinations (Table 4).

The high degree of IRAP polymorphism in this study indicated the suitability of IRAP as molecular makers for genotypic variability study of $S$. bicolor. A number of previous studies in other taxa of the Poaceae family also showed that IRAP markers produced high level of polymorphism such as in the genus Secale with polymorphism of $86 \%$ from four primers (Achrem et al. 2014 ), in rice with polymorphism of $96 \%$ from six primer combinations (Castelo et al. 2007), and in Sorghum halepense the polymorphism was $98.9 \%$ from eight primer combinations (Karimi and Saeidi 2016). IRAP, which produces data in the form of DNA fingerprinting, allowed simple and easy characterization of genotypes at intraspecific level (Madhusudhana et al. 2012). The suitability of IRAP as molecular marker for detecting variability at the genotype level has been reported by Cheragi et al. (2018) in 34 varieties of Lallemantia iberica, and by Vuorinen et al. (2018) in 150 genotypes of Triticum turgidum ssp. dicoccoides.

\section{Genotypic variability and relationships of $S$. bicolor accessions}

The result of cluster analysis on IRAP data using Manhattan distance and Neighbor-Joining method was presented as dendrogram (Figure 2) that showed the formation of two main clusters. The first cluster, marked as cluster A, consisted of 9 accessions which all of which were from the Special Province of Yogyakarta. Eight of the 9 accessions in this first cluster were those collected from Gunungkidul, and only one from Sleman. The second cluster was composed of 14 accessions, which most of them were collected from Central Java and East Java Provinces. This second cluster, marked as cluster B, was divided into two sub-clusters, denoted as B1 and B2. The members of sub-cluster B1 consisted of accessions from Yogyakarta and Central Java. Meanwhile, the sub-cluster B2 was composed of 9 accessions originating from Central Java and East Java. With such clustering patterns, it could be noted that the clustering of accessions into three groups showed a tendency of grouping based on geographical origin.

Similar grouping pattern was reported in a study of $S$. halepense in which cluster analysis and principal component analysis on IRAP markers showed the grouping of samples based on geographic origin (Karimi and Saeidi 2016). A study on genetic diversity of 47 barley genotypes using IRAP and retrotransposon-microsatellite amplified polymorphism (REMAP) also showed that result of cluster analysis was consistent with geographic origin (Singh et al. 2017). Similarly, molecular genotyping of sweet sorghum using SSR markers analyzed using NJ clustering method by Disasa et al. (2014) showed the grouping of accessions based on geographical origin. Recently, Ghonaim et al. (2020) in genetic diversity study of maize reported the clustering pattern resulted from retrotransposon data resulted in the grouping of samples based on ecogeographical origin. 
Table 4. Profiles of IRAP fingerprinting generated from 10 primer combinations

\begin{tabular}{lcccc}
\hline Primer combination & $\begin{array}{c}\text { Fragment length } \\
\text { (bp) }\end{array}$ & $\begin{array}{c}\text { Total number of } \\
\text { fragments }\end{array}$ & $\begin{array}{c}\text { Number of polymorphic } \\
\text { fragments }\end{array}$ & $\begin{array}{c}\text { Degree of } \\
\text { polymorphism }(\%)\end{array}$ \\
\hline Sukkula-Sukkula & $215-1800$ & 32 & 31 & 96.9 \\
Sukkula-RTY2 & $190-3450$ & 30 & 28 & 93.3 \\
RTY2-RTY2 & $390-2175$ & 16 & 12 & 75.0 \\
RTY1-3'LTR2 & $180-1900$ & 25 & 23 & 92.0 \\
3'LTR2-3'LTR2 & $225-1730$ & 17 & 15 & 88.2 \\
LTR6150-LTR6150 & $240-1640$ & 18 & 17 & 94.4 \\
RTY1W3-3'LTR2 & $120-2060$ & 26 & 24 & 92.3 \\
RTY1W7-3'LTR2 & $100-2925$ & 28 & 25 & 89.3 \\
RTY2W3-RTY2W3 & $350-3080$ & 20 & 17 & 85.0 \\
RTY2W8-RTY2W8 & $535-2730$ & 21 & 19 & 90.5 \\
Total & & 233 & 211 & 90.6 \\
Average & & & & \\
\hline
\end{tabular}

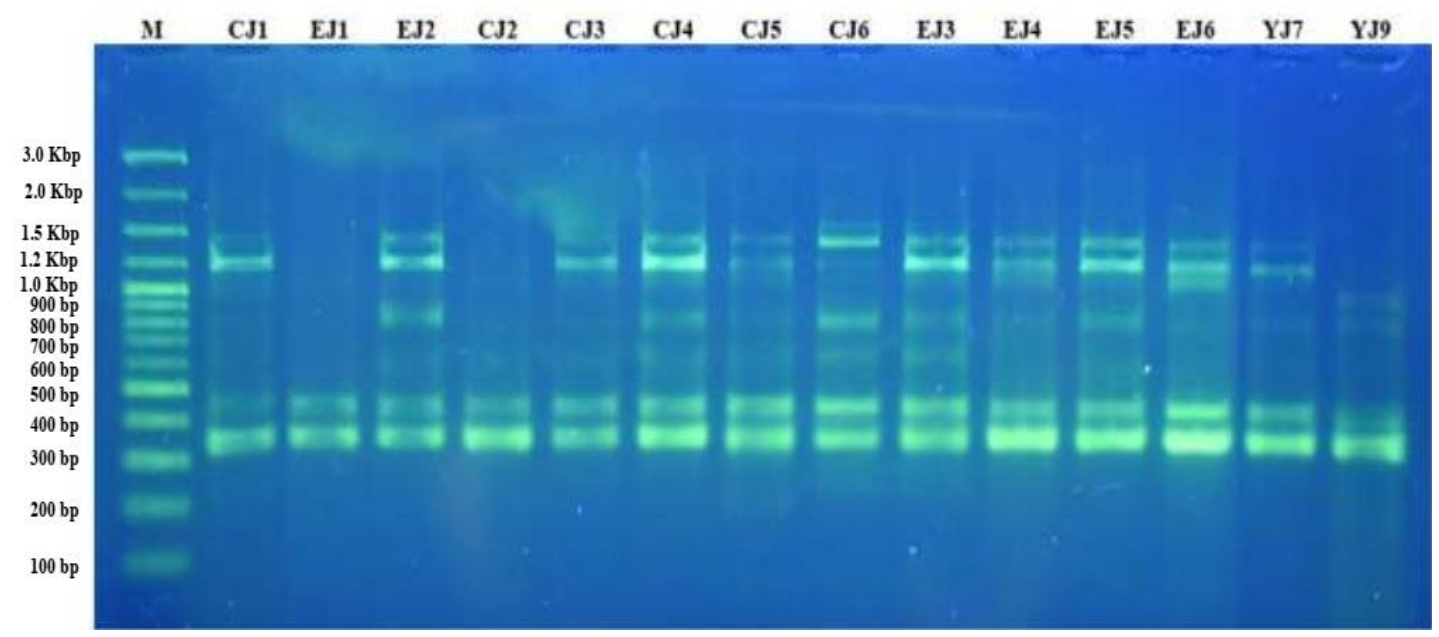

Figure 1. IRAP fingerprinting profile produced by 3'LTR2-3'LTR2 primer combination

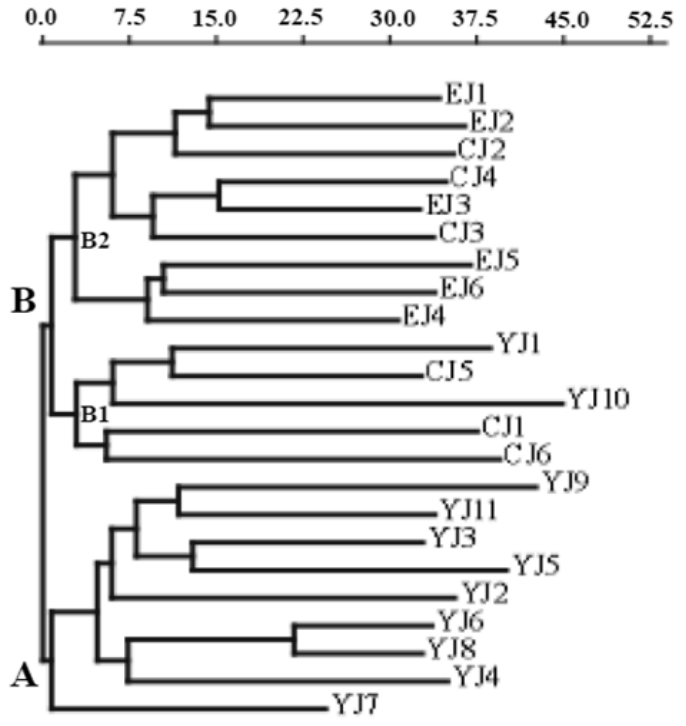

Figure 2. Neighbor-Joining dendrogram showing genotypic relationships of 23 sorghum accessions
The structure of the dendrogram figuring out the clustering of 23 accessions into three groups with varying degree taxonomic distance showed high genotypic variability. The high level of genotypic variability in each region in this study led to allegations on the role of farmers and their cultivation practices in maintaining the variability. All plant samples used in this study were collected from smallholder farmers who carry out traditional cultivation practices. They use seeds from the previous planting season as material for replanting in the following season. This practice has been done for long time from generation to generation. Traditional farmers grow sorghum races that can adapt well to their environment without knowing their diversity in terms of botanical racial classifications. In addition, the farmers sometimes obtain seeds from other areas through seed exchange activities. The seed exchange was the most reasonable explanation for the mixing of samples from Central Java (CJ2, CJ3, and CJ4) and East Java as found in sub-cluster B2. Meanwhile, the occurrence of samples from Yogyakarta in sub-cluster B1, in which most of samples were from Central Java, was due to the geographic proximity. Samples YJ1 and YJ10 
were collected from the area located on the border of these two regions. Based on these facts, the traditional cultivation and seed exchange practices apparently had strong influence on the grouping of accessions based on their geographic origin.

The role of farmers and the influence of their cultivation practices on the level of genotypic variability of sorghum have been reported in other countries. Barnaud et al. (2007) mentioned the role of farmers' selection, gene flow, seed exchange, and long-term adaptation to the local environment in shaping the genetic diversity of sorghum in Cameroon. A study by Khalsa (2013) in Africa showed that sorghum genetic diversity on local scale was structured based on geography, and was not much influenced by botanical race or climatic factors. Salih et al. (2016) who used NJ and PCoA in the assessment of genetic relationships of sorghum in Africa reported that the grouping of accessions was based on geographic origin. The result was interpreted as indication of gene flow and seed exchange between farmers from eastern and central Africa. The genetic diversity in crop plants was thought to be resulted from traditional cultivation practices in which farmers using small part of their harvest for replanting, and also due to plant's reproductive system through selffertilization. In this regard, Vigoroux et al. (2011) noted that traditional cultivation practices in which farmers sow seeds from their own harvest were influencing genetic diversity through selection, genetic drift, and gene flow. Similar cultivation practice was found in Ethiopia where farmers were consciously selecting to grow landraces that are suitable to agro-ecological conditions and their preferences for various uses (Desmae et al. 2016). All these prolong practices apparently bring a beneficial effect on the preservation of sorghum landraces in particular areas.

A scatterplot constructed from PCoA (Figure 3) emphasized the role of geographical origin in the grouping of accessions. This is particularly obvious when looking at the position of sub-cluster B1 which indicated the transition between clusters A and B. The spatial pattern of samples in PCoA scatterplot clearly showed that the grouping of genotypes in this study tends to be influenced by geographic proximity. This result indicated the role of geographical origin in shaping genotypic relationships. When taking together with clustering patterns in the dendrogram, the grouping of accessions in PCoA scatterplot indicated the adaptability of sorghum genotypes to different environments. In this regard, Desmae et al. (2016) who found similar patterns in Ethiopia argued that the grouping of sorghum landraces was influenced by geographical proximity and clinal trends. The grouping of accessions in this study which showed indications of local adaptations of sorghum genotypes was in line with the fact that sorghum is a crop plant having broad physiological adaptability to various environments (Badigannavar et al. 2018). Moreover, Tesfaye (2017) and Kebbede (2020) underlined that the high genotypic diversity in crop plants is often related to their ability to adapt to various environmental conditions.

The use of two multivariate analysis methods in this study, the cluster analysis, and principal coordinate analysis, was proved to be able in generating clear profile of genotypic variability and relationships of sorghum accessions. The genotypic variability of 23 sorghum accessions is high, as indicated by the spread of samples across four quadrants in two-dimensional plot of PCoA (Figure 3). The spread of accessions across four quadrants in the scatterplot indicated high genetic variability (Gerrano et al. 2014). PCoA is used as a complementary method to cluster analysis because this method is superior compared to other graphical dispersion analysis in terms of projection of distances representing the level of genetic diversity and identification of closely related genotype groups (Sant'Anna et al. 2020).

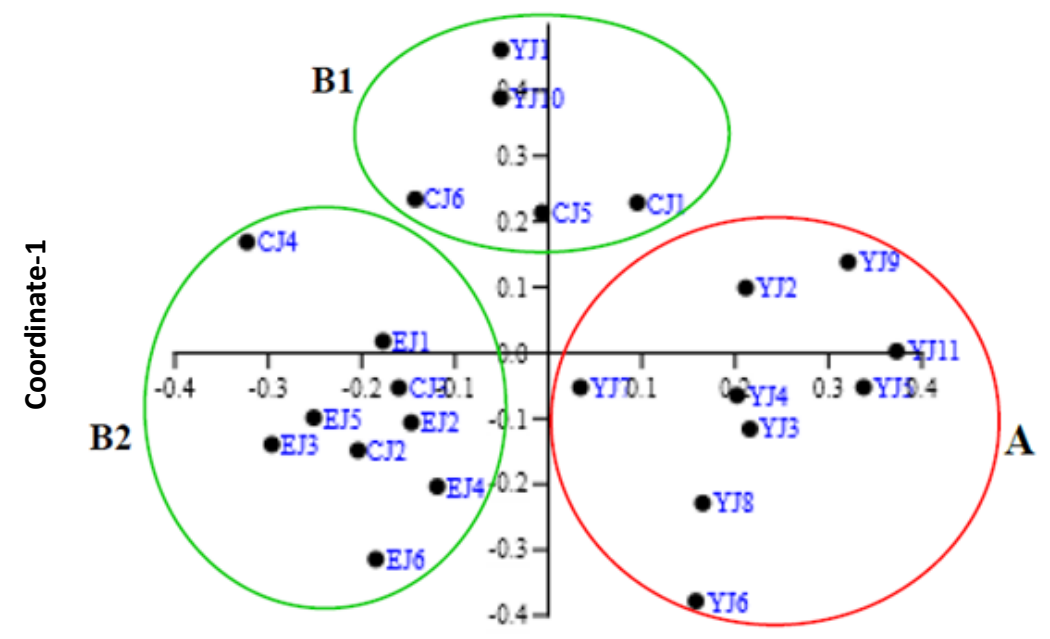

Coordinate-1

Figure 3. Scatterplot of 23 sorghum accessions based on IRAP fingerprinting data 
When the grouping of 23 sorghum accessions based on IRAP markers was compared to the grouping of botanical races based on morphological characters resulted from previous study (Martiwi et al. 2020), it was clear that there was no conformity between them. In this case, the accessions forming each cluster in NJ dendrogram have consisted of various botanical races. Cluster A consisted of Guinea, Caudatum, and Kaffir races, whereas cluster B showed higher diversity in which the 14 accessions were comprised of Bicolor, Guinea, Caudatum and Kaffir races. In general, the genotypic relationships of $S$. bicolor accessions in this study tend to be influenced by the geographic origin of the samples rather than the similarity of botanical races. Lack of conformity between morphological and molecular grouping might be attributed to the effect of genotype and environment interactions. In this regard, da Silva et al. (2017) noted that the difference in morphological and molecular grouping patterns can be caused by the influence of the interaction between the genotype and the environment. In the case of IRAP markers, Tagimanova et al. (2015) mentioned that if retrotransposons are considered as neutral components in plant DNA, then retrotransposons are independent of the phenotype. Moreover, the level of genotypic variability is often related to the ability of crop plants to adapt to the environment and the ability to tolerate changes in the environment that might lead to abiotic and biotic stress (Tesfaye et al. 2017). In order to find such relationship, Lasky et al. (2015) used single nucleotide polymorphism (SNP) variations in sorghum to study the association of SNPs with the environment in predicting phenotypic variations manifested in the form of adaptive traits, and found genomic basis for adaptation to the environment.

In conclusion, overall, results of this study supported the use of IRAP markers for the assessment of genotypic variability and genotypic relationships of S. bicolor. This study is the first to report the genotypic variability of sorghum in Indonesia using IRAP markers, and prove that genotypic variability of sorghum cultivated in Java Island is high. The existence of various botanical races at local scale indicated the role of smallholder farmers in preserving different genotypes of sorghum in their respective areas. The findings in this study bring beneficial impact for local farmers in understanding the diversity of genotypes as a basis for the improvement of this crop species through the application of breeding technology. Moreover, this research contributes to provide a basis for the development and preservation of sorghum as a potential crop to support food security programs.

\section{ACKNOWLEDGEMENTS}

This research is part of the Ph.D. thesis of the first author. This research was funded by a grant from Universitas Gadjah Mada, Yogyakarta, Indonesia under the scheme of Thesis Recognition Program (RTA contract no: 2488/UN1.P.III/DIT-LIT/PT/2020) granted for the corresponding author in her appointment as co-supervisor of the first author. Our great appreciation is delivered for
Suparjiyem (Female Food Heroes of Indonesia 2013), Esti Faizah (Agricultural Advisor for Babat-Lamongan region; member of the Indonesian Sorghum Community), and Agus S.W. Utomo (Agricultural Advisor for Raji-Demak region) for providing valuable information on farmers' agricultural practices.

\section{REFERENCES}

Achrem M, Kalinka A, Rogalska SM. 2014. Assessment of genetic relationships among Secale taxa by using ISSR and IRAP markers and the chromosomal distribution of the AAC microsatellite sequence. Turk J Bot 38: 213-225. DOI: 10.3906/bot-1207-26.

Alhajturki D, Al Jamali M, Kanbar A. 2011. Genetic variation of sorghum (Sorghum bicolor L. Moench) varieties assessed by ISSR markers. Adv Environ Biol 5 (11): 3504-3510.

Badigannavar A, Teme N, de Oliveira AC, Li G, Vaksmann M, Viana VE, Ganapathi TR, Sarsu F. 2018. Physiological, genetic and molecular basis of drought resilience in sorghum [Sorghum bicolor (L.) Moench]. Ind J Plant Physiol 23 (4): 670-688. DOI: 10.1007/s40502018-0416-2.

Barnaud A, Deu M, Garine E, McKey D, Joly HI. 2007. Local genetic diversity of sorghum in a village in northern Cameroon: structure and dynamics of landraces. Theor Appl Genet 114: 237-248. DOI: 10.1007/s00122-006-0426-8.

Berenji J, Dahlberg J, Sikora V, Latkovi D. 2011. Origin, history, morphology, production, improvement, and utilization of broomcorn [Sorghum bicolor (L.) Moench] in Serbia. Econ Bot 65 (2): 190-208. DOI: $10.1007 / \mathrm{s} 12231-011-9155-2$.

Castelo J. S. Branco, Eduardo A. Vieira, Gaspar Malone, Mauricio M. Kopp, Emilia Malone, Albina Bernardes, Claudete C. Mistura, Fernando I.F. Carvalho, Costa A. Oliveira. 2007. IRAP and REMAP assessments of genetic similarity in rice. J Appl Genet 48 (2): 107113.

Chavan SK Mahajan RC, Fatak SU. 2010. Genetic variability studies in sorghum. Karnataka J Agric Sci 23 (2): 322-323.

Cheraghi A, Rahmani F, Hassanzadeh-Ghorttapeh A. 2018. IRAP and REMAP based genetic diversity among varieties of Lallemantia iberica. Mol Biol Res Commun 7 (3): 125-132. DOI: 10.22099/mbrc.2018.29924.1327.

da Silva MJ, Pastina MM, de Souza VF, Schaffert RE, Carneiro PCS, Noda RW, Carneiro JES, Damasceno CMB, Parrella RAC. 2017. Phenotypic and molecular characterization of sweet sorghum accessions for bioenergy production. PLoS ONE 12 (8): e0183504. DOI: 10.1371 journal.pone.0183504.

Dahlberg J, Berenji J, Sikora V, Latković D. 2011. Assessing sorghum [Sorghum bicolor (L) Moench] germplasm for new traits: food, fuels $\&$ unique uses. Maydica 56-1750: 85-92

Desmae H, Jordan DR, Godwin ID. 2016. DNA markers reveal genetic structure and localized diversity of Ethiopian sorghum landraces. Afr J Biotechnol 15 (41): 2301-2311. DOI: 10.5897/AJB2016.15404.

Disasa T, Feyissa T, Admassu B, Paliwal R, Villiers S, Odeny DA. 2016. Molecular evaluation of Ethiopian sweet sorghum germplasm and their contribution to regional breeding programs. Aust J Crop Sci 10 (4): 520-527. DOI: 10.21475/AJCS.2016.10.04.P7286X.

Farouji AE, Khodayari H, Saeidi H, Rahiminejad MR. 2015. Genetic diversity of diploid Triticum species in Iran assessed using Interretroelement amplified Polymorphism (IRAP) markers. Biology 70 (1): 52-60. DOI: 10.1515/biolog-2015-0002.

Gerrano AS, Labuschagne MT, van Biljon A, Shargie NG. 2014. Genetic variability among sorghum accessions for seed starch and stalk total sugar. Sci Agric 71 (6): 472-479. DOI: 10.1590/0103-9016-20130322 .

Ghonaim M, Kalendar R, Barakat H, Elsherif N, Ashry N, Schulman AH. 2020. High-throughput retrotransposon-based genetic diversity of maize germplasm assessment and analysis. Mol Biol Rep 47: 15891603. DOI: 10.1007/s11033-020-05246-4

Gozukirmizi N, Yilmaz S, Marakli S, Temel A. 2015. Retrotransposonbased molecular markers; Tools for variation analysis in plants. In: Taški-Ajduković K (ed.). Applications of Molecular Markers in Plant Genome Analysis and Breeding. Research Signpost, Kerala, India. 
Hammer $\varnothing$, Harper DAT, Ryan PD. 2001. PAST: Paleontological statistics software package for education and data analysis. Palaeontologia Electronica 4 (1): 9pp. http: //palaeoelectronica.org/2001_1/past/issue1_01.htm.

Jiang S-Y, Ramachandran S. 2013. Genome-wide survey and comparative analysis of LTR retrotransposon and their captured genes in rice and $\begin{array}{lllll}\text { Sorghum. PLoS ONE } 8 & (7) \text { e } 71118 . & \text { DOI: }\end{array}$ 10.1371/journal.pone.0071118.

Kalendar R, Grob T, Regina M, Suoniemi A, Schulman AH. 1999. IRAP and REMAP: Two new retrotransposon-based DNA fingerprinting techniques. Theor Appl Genet 98: 704-711.

Kalendar R. Taskanen J, Imonen S, Nevo E, Schulman AH. 2000 Genome evolution of wild barley (Hordeum spotaneum) by BARE-1 retrotransposon dynamics in response to sharp microclimate divergence. Proc Natl Acad Sci USA 97: 6603-6607.

Karimi A, Saeidi H. 2016. Genetic diversity of Sorghum halepense (L.) Pers. in Iran as revealed by IRAP markers. Plant Genet Resour 14 (2): 132-141. DOI: $10.1017 /$ S1479262115000167.

Kebbede WY. 2020. Genetic Variability and Divergence in Sorghum: Review. Intl J Res Stud Agric Sci 6 (5): 11-20. DOI: DOI 10.20431/2454-6224.0605002.

Khalsa SDK. 2013. Genetic structure and diversity of Sorghum bicolor a three geographical scales in Africa. [Thesis]. Department of Biology, University of Oslo, Oslo, Norway.

Lasky JR, Upadhyaya HD, Ramu P, Deshpande S, Hash CT, Bonnette J, Juenger TE, Hyma K, Acharya C, Mitchell SE, Buckler ES, Brenton Z, Kresovich S, Morris GP. 2015. Genome-environment associations in sorghum landraces predict adaptive traits. Sci Adv 2015;1: e1400218. DOI: 10.1126/sciadv.1400218

Madhusudhana R, Balakrishna D, Rajendrakumar P, Seetharama N, Patil JV. 2012. Molecular characterization and assessment of genetic diversity of sorghum inbred lines. Afr J Biotechnol 11 (90): 1562615635. DOI: $10.5897 / \mathrm{AJB} 12.321$

Mansour A. 2008. Utilization of genomics retrotransposon as cladistic makers. J Cell Mol Biol 7: 17-28

Martiwi INA, Nugroho LH, Daryono BS, Susandarini R. 2020 Morphological variability and taxonomic relationship of Sorghum bicolor (L.) Moench accessions based on qualitative characters. Annu Res Rev Biol 35 (6): 40-52. DOI: 10.9734/ARRB/2020/v35i630234.

Mumtaz A, Hussain D, Saeed M, Arshad M, Yousaf MI. 2018. Estimation of genetic diversity in sorghum genotypes of Pakistan. J Natn Sci
Foundation Sri Lanka $46 \quad$ (3): 271-280. DOI: 10.4038/jnsfsr.v46i3.8479.

Ng'uni D, Geleta M, M Fatih M, Bryngelsson T. 2010. Phylogenetic analysis of the genus Sorghum based on combined sequence data from cpDNA regions and ITS generate well-supported trees with two major lineages. Ann Bot 105: 471-480. DOI: 10.1093/aob/mcp305.

Raza A, Ashraf F, Mehmood SS, Khan RSA. 2019. Evaluation of genetic diversity among exotic sorghum (Sorghum bicolor L. Moench) genotypes through molecular-based analysis (RAPD-PCR). Gesunde Pflanzen 71: 187-196. DOI: 10.1007/s10343-019-00464-8.

Salih SA, Herslman L, Labuschange MT, Mohammed CAH. 2016. Assessment of genetic diversity of sorghum [Sorghum bicolor (L.) Moench] germplasm in east and central Africa. World J Biotechnol 1 (3): 113-120.

Sant'Anna IC, Silva GN, Carneiro VQ, Pontes DS, Nascimento M, Cruz CD. 2020. of projection of distance techniques for genetic diversity studies. Acta Sci Agron 42: e42483. DOI: 10.4025/actasciagron.v42i1.42483.

Shirasu K, Schulman AH, Lahaye T, Schulze-Lefert P. 2000. A Contiguous $66-\mathrm{kb}$ barley DNA sequence provides evidence for reversible genome expansion. Genome Res 10: 908-915.

Singh S, Nandha PS, Singh J. 2017. Transposon-based genetic diversity assessment in wild and cultivated barley. Crop J 5: 296-304. DOI: 10.1016/j.cj.2017.01.003.

Tagimanova DS, Novakovskaya AP, Uvashov AO, Khapilina ON, Kalendar RN. 2015. Use of retrotransposon markers for analysing the genetic diversity of wild emmer wheat (Triticum dicoccoides). Biotechnol Theory Pract 4: 28-37. DOI: 10.11134/btp.4.2015.4.

Teo CH, Tan SH, Ho CL, Faridah QZ, Othman YR, Heslop-Harrison JS, Kalendar R, Schulman AH. 2005. Genome constitution and classification using retrotransposon-based markers in the orphan crop banana. J Plant Biol 48 (1): 96-105.

Tesfaye K. 2017. Genetic diversity study of sorghum (Sorghum bicolor (L.) Moenc) genotypes, Ethiopia. Acta Univ Sapientiae Agric Environ 9: 44-54. DOI: 10.1515/ausae-2017-0004.

Vigouroux ,Y Barnaud A, Scarcelli N, Thuillet A-C. 2011. Biodiversity, evolution and adaptation of cultivated crops. C. R. Biol 334: 450-457. DOI: 10.1016/j.crvi.2011.03.003.

Vuorinen AL, Kalendar R, Fahima T, Korpelainen H, Nevo E, Schulman AH. 2018. Retrotransposon-based genetic diversity assessment in wild emmer wheat (Triticum turgidum ssp. dicoccoides). Agronomy 8: 107. DOI: 10.3390/agronomy8070107. 